\title{
Direct Measurement of Performance: A New Era in Antimicrobial Stewardship
}

\author{
Majdi N. Al-Hasan ${ }^{1,2, *} \mathbb{C}$, Hana Rac Winders ${ }^{3}$,, P. Brandon Bookstaver ${ }^{3,4}{ }^{(D}$ and \\ Julie Ann Justo ${ }^{3,4} \mathbb{D}$ \\ 1 School of Medicine, University of South Carolina, Columbia, SC 29209, USA \\ 2 Department of Medicine, Division of Infectious Diseases, Palmetto Health University of South Carolina \\ Medical Group, Columbia, SC 29203, USA \\ 3 Department of Clinical Pharmacy and Outcomes Sciences, University of South Carolina College of Pharmacy, \\ Columbia, SC 29208, USA \\ 4 Department of Pharmacy, Prisma Health Richland, Columbia, SC 29203, USA \\ * Correspondence: majdi.alhasan@uscmed.sc.edu; Tel.: +1-803-540-1062; Fax: +1-803-540-1079
}

Received: 18 July 2019; Accepted: 21 August 2019; Published: 24 August 2019

check for updates

\begin{abstract}
For decades, the performance of antimicrobial stewardship programs (ASPs) has been measured by incidence rates of hospital-onset Clostridioides difficile and other infections due to multidrug-resistant bacteria. However, these represent indirect and nonspecific ASP metrics. They are often confounded by factors beyond an ASP's control, such as changes in diagnostic testing methods or algorithms and the potential of patient-to-patient transmission. Whereas these metrics remain useful for global assessment of healthcare systems, antimicrobial use represents a direct metric that separates the performance of an ASP from other safety and quality teams within an institution. The evolution of electronic medical records and healthcare informatics has made measurements of antimicrobial use a reality. The US Centers for Disease Control and Prevention's initiative for reporting antimicrobial use and standardized antimicrobial administration ratio in hospitals is highly welcomed. Ultimately, ASPs should be evaluated based on what they do best and what they can control, that is, antimicrobial use within their own institution. This narrative review critically appraises existing stewardship metrics and advocates for adopting antimicrobial use as the primary performance measure. It proposes novel formulas to adjust antimicrobial use based on quality of care and microbiological burden at each institution to allow for meaningful inter-network and inter-facility comparisons.
\end{abstract}

Keywords: Antibiotics; resistance; broad-spectrum agents; hospital epidemiology; antibiotic utilization; infection control; infection prevention; Pseudomonas aeruginosa; Acinetobacter baumannii; extended-spectrum beta-lactamases; carbapenem-resistant Enterobacteriaceae; methicillin-resistant Staphylococcus aureus

\section{Introduction: Importance of Antimicrobial Stewardship Metrics}

It is imperative for the success of any antimicrobial stewardship program (ASP) to have objective measures for performance evaluation. Direct measurement of ASP performance via process measures (e.g., antimicrobial use) and/or outcome measures (e.g., Clostridioides difficile infection [CDI]) is currently recommended by clinical guidelines to improve quality care and prevent antimicrobial resistance [1]. This process ensures that both hospital administration and ASP team members have consistent goals and expectations. It provides ASPs with the opportunity to periodically self-reflect on their performance and discuss long-term planning to achieve their aims. This also creates national and local standards to compare ASPs in different healthcare systems after adjustments for potential differences across institutions [1]. 
ASP metrics are often categorized by type into antimicrobial use (AU) measures, process measures, quality measures, costs and clinical outcome measures. Expert panels assembled among adult and pediatric stewards were challenged to develop a set of metrics perceived as both useful and logistically feasible for adoption by ASPs as performance metrics [2,3]. Variability in practice areas, institutions, resources and infrastructure all impede the utility of many proposed ASP metrics. The true impact of an ASP on quality and clinical outcome measures specifically is also debatable, given the patient complexities and confounders present. Do these metrics actually measure ASP "performance" or "value" or "efficiency", a combination of these factors, or none at all?

While several quantitative measures (e.g., antimicrobial use and costs) are often considered frontline metrics and central to ASP operations, noted expert stewards have proposed a shift in focus to quality and patient outcomes to demonstrate enhanced program value [4-6]. Many regulatory and quality improvement organizations (e.g., Agency for Healthcare Research and Quality) have established infectious diseases metrics designed to measure quality which are often tied to reimbursement [4]. The changing landscape of reimbursement in the US healthcare system and growing transparency of quality and safety measures through public reporting will likely impact ASPs and potentially influence key metrics tied to performance evaluation. Collaboration between ASPs, healthcare administration and quality divisions is imperative in order to maintain consistency in measured success. In this narrative review, we discuss the landscape of proposed ASP metrics and compare their value and utility as measures of ASP performance focusing on acute care hospitals.

\section{Dynamics of Antimicrobial Stewardship and Infection Prevention and Control Programs}

The re-emergence of CDI as a significant threat in the early 2000s was arguably the single most important factor increasing awareness of risks associated with antimicrobials at both the public and institutional level. The potential of patient-to-patient transmission of $C$. difficile spores make clusters or outbreaks of CDI an imminent threat to hospitals. CDI created a common target for both Infection Prevention and Control Programs and ASPs and facilitated a dynamic relationship between both teams. Contact isolation of hospitalized patients with CDI and hand hygiene of healthcare workers with soap and water have been the cornerstone of Infection Prevention and Control Program efforts to reduce transmission of $C$. difficile spores within the hospital. At the same time, reduction in unnecessary use of broad-spectrum antimicrobials may reduce the risk of hospital-onset CDI (HO-CDI). For this reason, many Infection Prevention and Control Programs started monitoring antimicrobial use in the hospital to enhance their CDI interventions, often utilizing the same team members. On other occasions, ASPs emerged under the Infection Prevention and Control Program umbrella. It was convenient to use the incidence rate of HO-CDI as a metric for both Infection Prevention and Control Programs and ASPs. The requirement for hospitals within the United States to publicly report the incidence rate of HO-CDI through National Healthcare Safety Network (NHSN) and paucity of other measures of ASP performance only emphasized this existing concept.

Similarly, institutional Infection Prevention and Control Programs have been monitoring and intervening to prevent patient-to-patient transmission of multidrug-resistant (MDR) bacteria: initially, extended-spectrum beta-lactamase-producing Enterobacteriaceae (ESBLE) and methicillin-resistant Staphylococcus aureus (MRSA), then carbapenem-resistant Enterobacteriaceae (CRE). Since antimicrobial use predisposes to colonization and infections with MDR bacteria $[7,8]$, incidence rates of infections or colonization with MDR bacteria were often used as a quality measure of ASP performance. Mandatory reporting of these infections added another layer of convenience.

Over time, ASPs have evolved and have become more focused on quality of patient care, including optimization of antimicrobial management. At the same time, C. difficile, MRSA and ESBLE have emerged as community-onset pathogens rather than predominant causes of nosocomial infections [9-12]. Antimicrobial resistance of predominantly hospital-onset bacteria, such as Pseudomonas aeruginosa and Acinetobacter baumannii, has become the most imminent threat to hospitals in the US [13]. 
Moreover, with the emergence of community-acquired MRSA, intravenous vancomycin has become the most commonly used antimicrobial in US hospitals. The increasing use of vancomycin, by itself or in combination with piperacillin/tazobactam, has contributed to an increase in antimicrobial-associated nephrotoxicity in hospitalized patients [14,15]. Monitoring the use of nephrotoxic antimicrobial agents has been added to the daily duties of ASPs. This shifting focus has allowed a greater degree of independence from Infection Prevention and Control Programs and has made it difficult to use the same personnel for both Infection Prevention and Control Programs and ASPs.

\section{Comparison of Various Antimicrobial Stewardship Metrics}

\subsection{Clostridioides difficile Infection}

Prevention of CDI is one of the main benefits of antimicrobial stewardship. Current or prior antimicrobial use contributes to CDI due to changes in intestinal microbiota and decreased competition against $C$. difficile [16]. Therefore, it is intuitive to use CDI as a measure of ASP performance in hospitals [1,2]. However, the multifactorial nature of CDI, possibility of person-to-person transmission irrespective of antimicrobial use and site of acquisition, and changing incidence rate of CDI based on diagnostic testing methods or algorithms, argue against its use as the primary ASP metric.

\subsubsection{Diagnosis}

CDI can only be diagnosed based on laboratory testing. Using a highly sensitive test, such as PCR, would increase the incidence of $\mathrm{CDI}$ compared to toxin $\mathrm{A} / \mathrm{B}$ antibody-antigen assays [17]. An increase in the incidence rate of $\mathrm{HO}-\mathrm{CDI}$ was observed when switching from toxin $\mathrm{A} / \mathrm{B}$ antibody-antigen testing to PCR [18]. The use of diagnostic tests with varying sensitivities makes comparison of HO-CDI incidence rates across hospitals impractical. A recent study demonstrated that only $20 \%$ of in-hospital testing for CDI was appropriate [19]. Inappropriate testing for CDI resulted in overtreatment and inaccurate publicly reported metrics [19]. Even when the same laboratory diagnostic test is used, a change in institutional policy or algorithm for CDI testing influenced CDI incidence rates. An institutional requirement for testing all hospitalized patients with liquid stools was associated with higher incidence rate of HO-CDI in Scotland [20]. C. difficile PCR does not differentiate colonization from infection. Given the large proportion of inappropriate CDI testing in hospitals, a clinical decision-making tool to improve the appropriateness of testing likely has a much higher impact in reducing HO-CDI rates than any ASP intervention. This confounding makes it difficult to correlate incidence of HO-CDI with ASP activities aiming to optimize antimicrobial use. Instead, this argues for design of a diagnostic stewardship metric in collaboration with microbiology, central laboratory and Infection Prevention and Control Programs.

\subsubsection{Relatively Low Incidence of CDI}

Most clinical studies of CDI adopt a case-control design due to the relative infrequency of CDI in hospitalized patients. In two cohorts, only $2-4 \%$ of hospitalized patients with gram-negative bloodstream infections developed CDI, despite receipt of broad-spectrum antimicrobial therapy [21,22]. Although still considered a major risk, the relatively large number needed to harm constitutes a challenge for ASPs attempting to demonstrate effectiveness of their interventions. Based on such data, ASPs are required to streamline or discontinue 25-50 courses of broad-spectrum antimicrobials to potentially prevent one case of CDI. Discontinuation of antimicrobial therapy is one of the most impactful outcomes of any ASP intervention; however, it is a much less frequent intervention than de-escalation of antimicrobial therapy or reduction in proposed treatment duration [23]. Designing an ASP intervention to reduce the incidence rate of CDI requires a tremendous amount of time, resources and dedication. This is likely the reason for the relatively small number of published studies demonstrating successful reduction in CDI via ASP interventions, despite several decades of focus in this area. To our knowledge, only early de-escalation of broad-spectrum antimicrobial therapy 
(within $48 \mathrm{~h}$ ) has been associated with a reduction in CDI risk [22]. Early de-escalation of antimicrobial therapy requires robust ASP, rapid diagnostics, timely electronic alerts, and experienced personnel to act on these alerts. Conventional de-escalation of antimicrobial therapy (after 4 days) has demonstrated non-inferiority to broad-spectrum therapy, but is yet to show a significant reduction in CDI [24].

\subsubsection{Multifactorial Etiology of CDI}

In addition to antimicrobials, many other independent risk factors have been associated with development of CDI, such as chemotherapy and proton-pump inhibitors [25]. Moreover, potential for person-to-person transmission of $C$. difficile spores makes Infection Prevention and Control Program efforts far more important than those of ASPs in reducing the incidence of HO-CDI. Given the large number of ASP interventions required to prevent CDI, a cluster of CDI in one unit of the hospital may cancel out an entire year's worth of ASP efforts. Another factor that has not been widely studied is the impact of antimicrobials used prior to hospital admission on the risk of HO-CDI. Hospital admissions secondary to community-onset CDI continue to rise and are not as intensely monitored by Infection Prevention and Control Programs or ASPs, but may also pose similar risk to institutional outbreaks. Most institutional ASPs have no control over antimicrobials received in ambulatory settings or other hospitals prior to referral.

\subsubsection{Difficulty of Designing a Successful ASP Intervention for CDI}

Although the association between antimicrobial use and CDI is strong, it remains controversial which antimicrobial agents/classes are more likely to contribute to CDI [26]. There is general agreement that the broader the spectrum of antimicrobials, the higher the risk of CDI; however, there are notable exceptions to this rule, such as clindamycin [27]. Interpretation of the literature is difficult, due to use of different definitions and inconsistent methodology. To increase sample size and power, community-onset and HO-CDI were merged despite vast differences in the spectrum of activity of oral and intravenous antimicrobials used in the two respective settings [28]. Moreover, all penicillins were classified in one category, despite the huge difference in the spectrum of activity of piperacillin-tazobactam and penicillin G, for example [29]. Even the well-designed interventions which have reported a reduction in the incidence rate of CDI after antimicrobial formulary changes did not assess the collateral damage of the intervention on antimicrobial resistance [20,30]. It is worrisome that some formulary restrictions designed for reducing CDI risk may encourage the use of antipseudomonal beta-lactams and carbapenems [30]. This contradicts recent large cohorts demonstrating the highest odds of CDI among hospitalized patients receiving antipseudomonal beta-lactams [22,31]. In addition, the linear increase in antimicrobial resistance of E. coli and other Enterobacteriaceae bloodstream isolates to aminopenicillins and first-generation cephalosporins limits de-escalation options from antipseudomonal beta-lactams to intravenous ceftriaxone or oral fluoroquinolones on many occasions [22,32,33]. The long-term consequences of increasing antimicrobial resistance rates to antipseudomonal beta-lactams and carbapenems secondary to excessive use may exceed any potential early benefits from this strategy [34,35]. A subtle decline in CDI at the expense of increasing antimicrobial resistance rates of already difficult to treat bacteria, such as $P$. aeruginosa and A. baumannii, constitutes one step forward and two steps back for the longevity of the ASP and the institution.

\subsection{Incidence Rates of Infections or Colonization with MDR Bacteria}

\subsubsection{Extended-Spectrum Beta-Lactamase-Producing Enterobacteriaceae (ESBLE)}

Controlling outbreaks and reducing transmission of ESBLE in the hospital setting have been common goals for both Infection Prevention and Control Programs and ASPs since this resistance mechanism was first described in 1983 [36]. This is conceivable since exposure to antimicrobials, particularly beta-lactams and fluoroquinolones, is a risk factor for infection or colonization with ESBLE $[7,8]$. 
Moreover, ESBLE may be transmitted from person-to-person within hospitals or other settings. At the turn of the century, ESBLE emerged as community-onset bacteria likely due to availability and widespread use of broad-spectrum oral antimicrobials in the community, such as extended-spectrum cephalosporins and fluoroquinolones $[11,37]$. The incidence rate of hospital-acquired ESBLE infections have remained relatively stable over the past decade, due to effective Infection Prevention and Control Programs and ASPs [12]. On the other hand, the lack of such programs in ambulatory settings and long-term care facilities has contributed to an increase in the incidence rate of community-onset ESBLE infections [12]. It is estimated that $80 \%$ of ESBLE infections in the US are acquired outside the hospital [8,12].

Another limitation of using ESBLE as a measure of ASP performance is the lag between ESBLE colonization and infection. Colonization with ESBLE within the past one year has been associated with increased risk of ESBLE infections [8,38]. Patients may be colonized with ESBLE due to antimicrobial use in the community. If a urinary culture is obtained on the fourth day of hospitalization for appropriate or inappropriate indications, the ESBLE isolate will be classified as nosocomial, even in the absence of any antimicrobial use during the index hospitalization [39]. This limits the utility of ESBLE as a measure of ASP performance.

\subsubsection{Methicillin-Resistant Staphylococcus aureus (MRSA)}

The emergence of MRSA as community-acquired bacteria by the end of last century makes the incidence of hospital-onset MRSA infections or colonization a less useful ASP metric. There is a suggestion that antimicrobial use may predispose to MRSA colonization or infection. A recent study demonstrated that the restriction of fluoroquinolone and macrolide use, among other antimicrobials, was associated with a reduction in MRSA infection rates [40]. However, this association was temporal, at best, and a decline in MRSA infection/colonization rates was demonstrated elsewhere without formulary changes [41-43]. In the era of increasing antimicrobial resistance rates, class restrictions of already limited antimicrobial treatment options for hospitalized patients with serious infections seem counterproductive. Given the high prevalence of community-acquired MRSA strains and widespread use of fluoroquinolones in the community, it is unrealistic to expect formulary restrictions of fluoroquinolones in hospitals to impact overall MRSA rates. Restricting fluoroquinolone use in the community to specific indications, such as acute pyelonephritis and community-onset pneumonia, seems more reasonable [44].

\subsubsection{Carbapenem-Resistant Enterobacteriaceae (CRE)}

Carbapenem exposure is a risk factor for CRE infections or colonization [45]. Since carbapenems are currently only available in intravenous form in the US, the incidence rate of CRE appears more relevant to institutional ASPs than that of ESBLE and MRSA. The potential for person-to-person transmission have made long-term care facilities reservoirs for CRE, likely due to lack of effective Infection Prevention and Control Programs and ASPs. The lag between CRE colonization and infection, as well as the potential for receiving carbapenems at other facilities, pose some limitations to using CRE incidence rates to evaluate ASP performance. The potential availability of oral carbapenems in the US in the near future may change the epidemiology of CRE infections, in an unfortunate repeat of the community-onset ESBLE phenomenon.

\subsubsection{Antimicrobial-Resistant P. aeruginosa and A. baumannii}

P. aeruginosa and A. baumannii are predominantly hospital-onset pathogens [46]. They are ubiquitous bacteria which are difficult to eliminate from hospital environments. Hospitalized patients may become colonized with these bacteria due to either heavy exposure from prolonged hospitalization or antimicrobial selection pressure $[47,48]$. The presence of open wounds, mechanical ventilation, and urinary or central venous catheters place hospitalized patients at higher risk of infections with these bacteria $[46,49,50]$. Resistance to antipseudomonal beta-lactams and carbapenems among these isolates poses serious challenges to hospitals due to the lack of safe and effective antimicrobial treatment options [35]. 
Outbreaks of infections due to MDR P. aeruginosa and A. baumannii are devastating to both patients and hospitals, associated with high mortality rates and high costs of treatment. The amount of time, resources and personnel dedicated to the containment of such outbreaks is enormous, occasionally requiring unit closures and massive financial burdens [51,52]. For this reason, P. aeruginosa and A. baumannii are at the top of the World Health Organization global list of critical priority [13].

Inpatient antimicrobial use is by far the most important factor influencing antimicrobial resistance rates of these hospital-onset isolates [53-57]. The recent increase in utilization of antipseudomonal beta-lactams and carbapenems in US hospitals has been temporally associated with an increase in antimicrobial resistance rates of $P$. aeruginosa [34,35]. Using antimicrobial resistance of $P$. aeruginosa and A. baumannii as an ASP metric is logical and reasonable, but has limitations. First, changes in referral patterns may impact antimicrobial resistance at tertiary care centers. Second, nearly one-half of $P$. aeruginosa bloodstream isolates are acquired outside the hospital [48]. Community-onset P. aeruginosa infections are particularly common among immune compromised hosts and patients who received recent beta-lactams [48-50]. Antimicrobial resistance rates of strictly hospital-onset P. aeruginosa and A. baumannii isolates are a more equitable measure of ASP performance. This requires stratification by site of acquisition. If such stratification is not automated by clinical informatics, then resistance rates of hospital-onset isolates will have to be done manually. This is unlikely to be feasible for many ASPs, based on current resources in time and personnel.

\subsection{Quality of Care}

Quality of patient care is the most important antimicrobial stewardship principle [2-5]. The ultimate goal of ASPs is to optimize both empirical and definitive antimicrobial therapy for hospitalized patients with serious infections.

\subsubsection{Appropriate Definitive Antimicrobial Therapy}

Many ASPs utilize available healthcare informatics resources to identify suboptimal antimicrobial use among individual patient cases. The objective is to ensure patients who have positive clinical cultures, particularly from sterile sites, receive the most effective antimicrobial therapy. Appropriate therapy is not only a matter of receiving an antimicrobial agent with in vitro susceptibility against the microbial isolate. Rather, it is based on effectiveness as derived from large clinical studies and involves receiving an appropriately dosed agent based on the primary source of infection, the patient's renal and hepatic function, and the minimal inhibitory concertation of the clinical isolate. The antimicrobial should also be administered via the appropriate route based on severity of infection, reliability of the enteral route, and bioavailability of the agent [58-60].

Since most currently available software for identification of bug-drug mismatches use in vitro susceptibility as a screening measure for appropriateness, many patients receiving inappropriate definitive therapy will not be identified. This includes patients receiving antimicrobial agents without activity at the site of the infection (e.g., daptomycin for MRSA pneumonia or nitrofurantoin for E. coli bloodstream infections). It would require a separate ASP intervention to review all cases of pneumonia or bloodstream infection to identify such cases. The variety of factors associated with the "appropriateness" of antimicrobial therapy makes it difficult to measure ASP performance based on this metric alone.

\subsubsection{Appropriate Empirical Antimicrobial Therapy}

Receipt of appropriate empirical antimicrobial therapy is independently associated with survival and shorter duration of hospitalization in patients with serious bacterial infections [58,59,61-63]. Despite the excessive use of broad-spectrum agents in hospitals, up to $30 \%$ of patients still receive inappropriate empirical therapy [64]. As the focus of ASPs has shifted to quality, many ASPs have invested in measuring and improving the appropriateness of empirical therapy. The art is designing institutional management guidelines which increase the appropriateness of empirical therapy while 
also reducing overall use of broad-spectrum agents [65]. Institutional management guidelines based on local evidence, coupled with rapid microbial identification and vigorous ASP monitoring, have been demonstrated to successfully achieve both goals [66]. The proportion of patients receiving appropriate empirical antimicrobial therapy for serious infections is the most important measure for the quality of ASP performance. Many host factors, including age, comorbidities and acute severity of illness, impact both survival and hospital length of stay in patients with serious bacterial infections $[58,63,67,68]$. In reality, the only variable an ASP can directly control and modify is the selection of empirical antimicrobial therapy. In order to use appropriateness of empirical therapy as a metric for ASP performance, it would require identification of every patient with a particular clinical syndrome (e.g., bloodstream infections, sepsis, or pneumonia) or a representative random sample. Although this may be time-consuming and labor-intensive, many ASPs are currently monitoring the appropriateness of empirical therapy, particularly in patients with bloodstream infections [66,69-72].

\subsection{Cost of Healthcare}

Antimicrobial cost was, for the most part, the only specific measure of ASP performance. Nonetheless, an institutional antimicrobial budget may be influenced by changes in acquisition price or renegotiation of institutional contracts, as dictated by supply and demand in the market.

Cost reduction has historically been used to justify the presence of an ASP, including both the establishment of a new program and maintenance of an existing program. ASPs have demonstrated significant reductions in hospitals' antimicrobial budgets, mostly by targeting and restricting unnecessary use of expensive antimicrobials (e.g., daptomycin, ceftaroline) [73-76]. However, cost savings generally plateau after few years. The cost of the acquisition of antimicrobials varies across institutions based on purchase volume and the ability of the healthcare system to negotiate a better deal. Occasional price hikes of commonly used agents make cost a less attractive metric. More importantly, the biggest cost savings institutional ASPs provide are hard to measure. These cost savings include reduction in length of hospital stay by improving the appropriateness of empirical antimicrobial therapy for serious infections $[62,63]$. Second, measurement of cost avoidance is also challenging. An ASP's efforts in reducing antimicrobial resistance rates of hospital-onset bacteria minimizes the need for new and often expensive antimicrobials used for treatment of infections due to MDR bacteria (e.g., ceftolozane/tazobactam, ceftazidime/avibactam).

\subsection{Antimicrobial Use}

\subsubsection{Direct and Specific ASP Metric}

Since ASPs manage antimicrobial therapy on a daily basis, harnessing antimicrobial use as the primary ASP metric is intuitive. Antimicrobial use represents the most direct measure of ASP performance. Most other metrics (e.g., CDI, MDR bacteria, and cost) provide indirect assessment of antimicrobial use. The assumption is that the higher the antimicrobial use within a hospital, the higher the HO-CDI and antimicrobial resistance. Contrary to incidence rates of HO-CDI and infections with MDR bacteria, institutional antimicrobial use is not affected by antimicrobials used outside the hospital. In addition, since the incidence of HO-CDI and infections with MDR bacteria may be reduced by Infection Prevention and Control Program efforts, antimicrobial use remains the only metric which differentiates the performance of ASPs from other patient safety and quality teams.

\subsubsection{Antimicrobial Use of Broad-Spectrum Agents}

ASP priority should be given for measuring antimicrobial use of broad-spectrum agents, such as antipseudomonal beta-lactams and carbapenems. For long-term monitoring, it would be useful to measure collective antimicrobial use of all antipseudomonal beta-lactams (e.g., piperacillin/tazobactam, cefepime, meropenem). This would avoid fluctuations associated with a temporary shortage of one agent. Monitoring intravenous vancomycin use is also important given the potential risk of nephrotoxicity $[14,15]$. 
Monitoring aminoglycosides use is equally important, particularly in institutions with frequent use of aminoglycoside combination regimens. Measurement of antimicrobial use of commonly used agents for treatment of community-onset infections, such as third-generation cephalosporins and fluoroquinolones, is also useful to ensure antipseudomonal beta-lactams and carbapenems are not completely replaced by agents which are still associated with a high risk of CDI. It would be reasonable to monitor institutional antimicrobial use of all agents, resources permitting, in order to ensure a decline of overall antimicrobial use in the hospital. However, most ASPs would not be bothered if the decline in antimicrobial use of broad-spectrum agents was accompanied by an increase in antimicrobial use of narrower-spectrum agents (e.g., penicillin G, nafcillin, ampicillin/sulbactam, cefazolin). After all, this is reflective of their hard work in de-escalation of broad-spectrum antimicrobial therapy.

\subsubsection{Benefits of Reducing Antimicrobial Use}

A reduction in antimicrobial use of antipseudomonal beta-lactams and other broad-spectrum agents is possible through syndrome-specific and other ASP interventions [72]. In addition, monitoring antimicrobial use is also rewarding for an ASP as a decline in antimicrobial use of broad-spectrum agents may be observed as early as 6 months following a successful intervention $[72,77,78]$. In the long-term, reduction in antimicrobial use of broad-spectrum agents will result in a decline in HO-CDI and antimicrobial resistance assuming there are no major changes in the healthcare system (e.g., referral patterns, outpatient antimicrobial prescription rates, clusters of HO-CDI or MDR bacteria).

\subsubsection{Measurement of Antimicrobial Use}

There are advantages and disadvantages of using days of therapy (DOT) or defined daily dose (DDD) as measures of antimicrobial use which are beyond the scope of this review. However, the goal of an ASP is to optimize, rather than minimize, antimicrobial therapy. Using DDD as a measure of antimicrobial use may punish ASPs for optimization of antimicrobial regimens in patients who truly need high doses of antimicrobials, such as patients with serious infections and augmented renal clearance. Conversely, institutions with relatively high rates of acute kidney injury due to heavy use of nephrotoxic agents may benefit from measuring DDD rather than DOT. Overall, DOT seems a fair indicator of performance for a local ASP.

An added benefit of antimicrobial use measurement is the frequent ability to stratify antimicrobial use by location and by time. This requires detailed knowledge of the denominator used in the generation of the antimicrobial use measurement, i.e., patient-days or the newer standard, days-present. Such data allows antimicrobial use to be locally compared across locations, such as hospital campus (in a multi-campus health system) or hospital unit, and by time, such as calendar month. This, in turn, helps ASPs identify areas within the institution where antimicrobial use appears excessive and helps design unit-specific or other targeted interventions.

\section{Proposed Novel Antimicrobial Use (AU) Metrics}

\subsection{Adjustment of AU by Quality of Care}

AU by itself is a measure of quantity, not quality of care. It would be valuable to provide reassurance that a reduction in AU of broad-spectrum agents is not achieved at the expense of appropriateness of therapy. Adjusting AU of broad-spectrum agents to the proportion of patients receiving appropriate empirical therapy incorporates quality of care and AU in one formula (Equation (1)):

$$
A U_{\text {adjusted } Q}=\frac{A U_{\text {local }}}{P_{\text {appropriate }}}
$$

Equation (1): Antimicrobial use adjusted by quality of care as determined by appropriateness of empirical antimicrobial therapy. 
Where $A U_{\text {adjusted } \mathrm{Q}}$ is the adjusted $\mathrm{AU}$ by quality of care at an institution, $A U_{\text {local }}$ is the raw $\mathrm{AU}$ at a particular local institution; $P_{\text {appropriate }}$ is the proportion of patients receiving appropriate empirical antimicrobial therapy at that facility.

For example, using $100 \mathrm{DOT} / 1000$ patient-days of antipseudomonal beta-lactams to provide appropriate empirical therapy to $90 \%$ of patients with gram-negative bloodstream infections at hospital $\mathrm{A}$ is better than using the same amount to cover only $80 \%$ appropriately at hospital B $(100 / 0.9=111$ vs. $100 / 0.8=125)$. This formula implies it would have taken 111 and 125 DOT/1000 patient-days, respectively, to provide appropriate empirical therapy to virtually all patients with this clinical syndrome at hospitals A and B, respectively (Table 1). This provides an assessment of the quantitative (AU) and qualitative (appropriateness of empirical antimicrobial therapy) performance of ASPs. It should be noted that antimicrobial resistance rates at an institution may influence the proportion of patients receiving appropriate empirical therapy.

Table 1. Proposed novel metrics for adjustment of antimicrobial use by quality of care.

\begin{tabular}{|c|c|}
\hline Adjusted AU & Formula \\
\hline \multirow[b]{2}{*}{ APBL } & $A U_{A P B L}$ \\
\hline & $\begin{array}{l}\text { Proportion of patients with gram-negative BSI or sepsis } \\
\text { receiving appropriate empirical antimicrobial therapy }\end{array}$ \\
\hline \multirow[b]{2}{*}{ Carbapenems } & $A U_{\text {Carbapenems }}$ \\
\hline & $\begin{array}{l}\text { Proportion of patients with gram-negative BSI or sepsis } \\
\text { receiving appropriate empirical antimicrobial therapy }\end{array}$ \\
\hline \multirow[b]{2}{*}{ Anti-MRSA agents } & $A U_{\text {Anti-MRSA agents }}$ \\
\hline & $\begin{array}{l}\text { Proportion of patients with gram-positive BSI or sepsis } \\
\text { receiving appropriate empirical antimicrobial therapy }\end{array}$ \\
\hline \multirow[b]{2}{*}{ Anti-VRE agents } & $A U_{\text {Anti-VRE agents }}$ \\
\hline & $\begin{array}{l}\text { Proportion of patients with gram-positive BSI or sepsis } \\
\text { receiving appropriate empirical antimicrobial therapy }\end{array}$ \\
\hline
\end{tabular}

Note: AU: antimicrobial use; APBL: antipseudomonal beta-lactams; MRSA: methicillin-resistant Staphylococcus aureus; VRE: vancomycin-resistant Enterococcus species; BSI: bloodstream infections.

Many ASPs are currently involved in management of bloodstream infections in order to optimize empirical therapy. The proportion of patients with bloodstream infections receiving appropriate empirical therapy is already available at such institutions [66,69-71]. Moreover, as institutions adopt new bundles for improvement of survival in patients with sepsis, it would be useful to measure the appropriateness of empirical antimicrobial therapy as part of this bundle. These bloodstream infection and sepsis cohorts may be used as representative samples for the adjustment of AU by the quality of care received at each institution.

\subsection{Adjustment of AU by Institutional Microbiological Burden}

Similar to any other ASP metric, comparisons of AU across institutions are not valuable without taking into account the differences in patient populations and microbiological burden at these facilities. For example, there is a wide variation in the incidence of P. aeruginosa among gram-negative bacteria at various institutions with higher incidence at tertiary care referral centers than community hospitals [79]. Since broad-spectrum antimicrobial agents are used to treat infections due to certain bacteria (e.g., antipseudomonal beta-lactams for P. aeruginosa), it is reasonable to adjust for the incidence of such isolates at a particular institution. Equation (2) can be used to adjust AU by institutional microbiological burden:

$$
A U_{\text {adjustedM }}=\frac{A U_{\text {local }}}{\left(\frac{I_{\text {local }}}{I_{\text {overall }}}\right)}
$$

Equation (2): Antimicrobial use adjusted by microbiological burden at the institution. 
Where $A U_{\text {adjustedM }}$ is the adjusted AU of antipseudomonal beta-lactams by microbiological burden at an institution, $A U_{\text {local }}$ is the raw $\mathrm{AU}$ of antipseudomonal beta-lactams at a particular local institution, $I_{\text {local }}$ is the incidence of the relevant organism(s) (i.e., P. aeruginosa) at that local institution, and $I_{\text {overall }}$ is its average incidence within the overall network or region.

As an example, $A U_{\text {local }}$ of antipseudomonal beta-lactams at hospitals A (tertiary care medical center) and B (rural community hospital) are both reported as 100 DOT/1000 patient-days. The $I_{\text {overall }}$ is 0.12 (12\% of all gram-negative isolates within this network or region are P. aeruginosa, for instance). $I_{\text {local }}$ for hospitals $\mathrm{A}$ and $\mathrm{B}$ are 0.15 and 0.09 , respectively. $A U_{\text {adjustedM }}$ of antipseudomonal beta-lactams at hospitals A and B could then be calculated as 100/(0.15/0.12) = 80 and 100/(0.09/0.12) = 133, respectively. The adjustments indicate that hospitals $\mathrm{A}$ and $\mathrm{B}$ would have utilized 80 and 133 DOT/1000 patient-days of antipseudomonal beta-lactams, respectively, if the proportion of $P$. aeruginosa isolates at both institutions were comparable to the overall network/regional average. Using 100 DOT/1000 patient-days of antipseudomonal beta-lactams may be justifiable in hospital A due to high microbiological burden, but seems excessive in hospital B.

Similar adjustments may be made for AU of anti-MRSA agents relative to the proportion of MRSA among all gram-positive isolates and AU of carbapenems based on proportion of ESBL-producing or ceftriaxone-resistant E. coli, Klebsiella species, and Proteus mirabilis (Table 2).

Table 2. Proposed novel metrics for adjustment of antimicrobial use by microbiological burden at each healthcare facility.

\begin{tabular}{cc}
\hline Adjusted AU & Formula \\
\hline APBL & $\frac{A U_{A P B L}}{\left(\frac{\text { Incidence of } P \text {. aeruginosa at local institution }}{\text { Average overall incidence of } P \text {. aeruginosa in network }}\right)}$ \\
\hline Carbapenems & $\frac{A U_{\text {Carbapenems }}}{\left(\frac{\text { Incidence of ESBLE at local institution }}{\text { Average overall incidence of ESBLE in network }}\right)^{*}}$ \\
\hline Anti-MRSA agents & $\frac{A U_{\text {Anti-MRSA agents }}}{\left(\frac{\text { Incidence of MRSA at local institution }}{\text { Average overall incidence of } M R S A \text { in network }}\right)}$ \\
\hline Anti-VRE agents & $\frac{A U_{\text {Anti-VRE agents }}}{\left(\frac{\text { Incidence of VRE at local institution }}{\text { Average overall incidence of VRE in network }}\right)}$ \\
\hline
\end{tabular}

Note: AU: antimicrobial use; APBL: antipseudomonal beta-lactams; ESBLE: extended-spectrum beta-lactamaseproducing Enterobacteriaceae; MRSA: methicillin-resistant Staphylococcus aureus; VRE: vancomycin-resistant Enterococcus species. * If microbiology laboratories in one or more hospitals in the network do not perform the ESBL screening test, then the incidence of ceftriaxone-resistant Enterobacteriaceae may be used alternatively to calculate adjusted carbapenem utilization in all hospitals in the network.

To our knowledge, these novel AU metrics in Section 4 have not been proposed in prior reviews of the literature. While their simple calculation is logical and represents a reasonable approach to AU interpretation, further research is warranted to validate these metrics in the clinical setting.

\section{NHSN Antimicrobial Use and Resistance Module}

The US Centers for Disease Control and Prevention (CDC) NHSN offers an antimicrobial use and resistance module with AU and AR options [80,81]. Facilities can participate in one or both options, but at this time, neither is required.

\subsection{Antimicrobial Use (AU) Option}

The AU option facilitates risk-adjusted inter- and intra-facility benchmarking of antimicrobial use [80]. Primarily, antimicrobial use is measured as antimicrobial DOT/1000 days-present. Antimicrobial use is aggregated by month for each patient care location and facility-wide. Antimicrobial use is also separated by the spectrum of the antimicrobials into 6 categories (Table 3). The data are then analyzed, and facilities receive a Standardized Antimicrobial Administration Ratio (SAAR) for each category and total antimicrobials in each patient care location and facility-wide. A SAAR of 1 indicates 
antimicrobial use is equivalent to referent populations. A SAAR greater than 1 that achieves statistical significance demonstrates excessive antimicrobial use, and a SAAR significantly lower than 1 may demonstrate underuse. SAAR still does not take into account quality of care (e.g., appropriateness of antimicrobial therapy). It does, however, attempt to control for institutional specifics, such as hospital size and complexity of patient population. The ability to look specifically at the different categories of antimicrobials is important, as ASPs are focused on decreasing broad-spectrum antimicrobials and increasing use of narrow-spectrum agents. This still constitutes a positive change for the institution, especially if SAAR for overall antimicrobials is equivalent to, or smaller than, 1 , as it implies successful de-escalation from broad- to narrower-spectrum agents.

Table 3. Centers for Disease Control and Prevention National Healthcare and Safety Network antimicrobial use module categories.

\begin{tabular}{cc}
\hline Category & Commonly Used Antimicrobials \\
\hline $\begin{array}{c}\text { Broad-spectrum agents predominantly used } \\
\text { for hospital-onset infections }\end{array}$ & $\begin{array}{c}\text { Piperacillin/tazobactam, ceftazidime, cefepime, meropenem, } \\
\text { imipenem/cilastatin, aztreonam, gentamicin, tobramycin }\end{array}$ \\
\hline $\begin{array}{c}\text { Broad-spectrum agents predominantly used } \\
\text { for community-acquired infections }\end{array}$ & $\begin{array}{c}\text { Ceftriaxone, cefotaxime, cefuroxime, cefdinir, ertapenem, } \\
\text { ciprofloxacin, levofloxacin, moxifloxacin }\end{array}$ \\
\hline $\begin{array}{c}\text { Agents predominantly used for resistant } \\
\text { gram-positive infections }\end{array}$ & Vancomycin, daptomycin, linezolid, ceftaroline \\
\hline $\begin{array}{c}\text { Narrow-spectrum beta-lactam agents } \\
\text { Agents posing the highest risk for } \\
\text { C. difficile infection }\end{array}$ & $\begin{array}{c}\text { Penicillin G, ampicillin, amoxicillin, ampicillin/sulbactam, } \\
\text { amoxicillin/clavulanate, nafcillin, dicloxacillin, cefazolin, } \\
\text { cephalexin, cefoxitin }\end{array}$ \\
\hline $\begin{array}{c}\text { Antifungal agents predominantly used for } \\
\text { invasive candidiasis }\end{array}$ & $\begin{array}{c}\text { Clindamycin, cefepime, ceftriaxone, cefdinir, ciprofloxacin, } \\
\text { levofloxacin, moxifloxacin }\end{array}$ \\
\hline
\end{tabular}

An example of such a comparison is provided in Figure 1. Such a line graph allows for a local ASP to evaluate their SAAR data over time. The monthly SAAR for all adult antibacterial agents facility-wide is in bold as an overall metric for antimicrobial use. Relevant subcategories are then superimposed on the same graph to allow for simple visual comparison and analysis by the ASP. Because subcategories for antibacterial agents are only available from NHSN for either adult intensive care units (ICUs) (Figure 1A) or adult wards (Figure 1B), the two line graphs are generated to assess antimicrobial use in each unit type. In this example, the adult facility-wide SAAR for overall antimicrobials remains below 1 for the entire time period. Broad-spectrum antimicrobials in adult ICUs are also consistently under 1, yet use of narrow-spectrum beta-lactams in adult ICUs is routinely above 1.0. This suggests that the observed use of agents such as penicillin G, ampicillin, nafcillin, and cefazolin was significantly greater than predicted by the NHSN model. Again, this antimicrobial use metric cannot assess quality of care. In order to distinguish whether this narrow spectrum beta-lactam use represents an appropriate de-escalation that an ASP can celebrate, versus an aggressive de-escalation which needs to be addressed by the ASP, this SAAR data would have to be coupled with quality of care data from the ICUs, e.g., appropriateness of therapy as previously discussed. In this way, SAAR data can reveal interesting nuances to guide local ASP assessments and subsequent initiatives. 
0.5

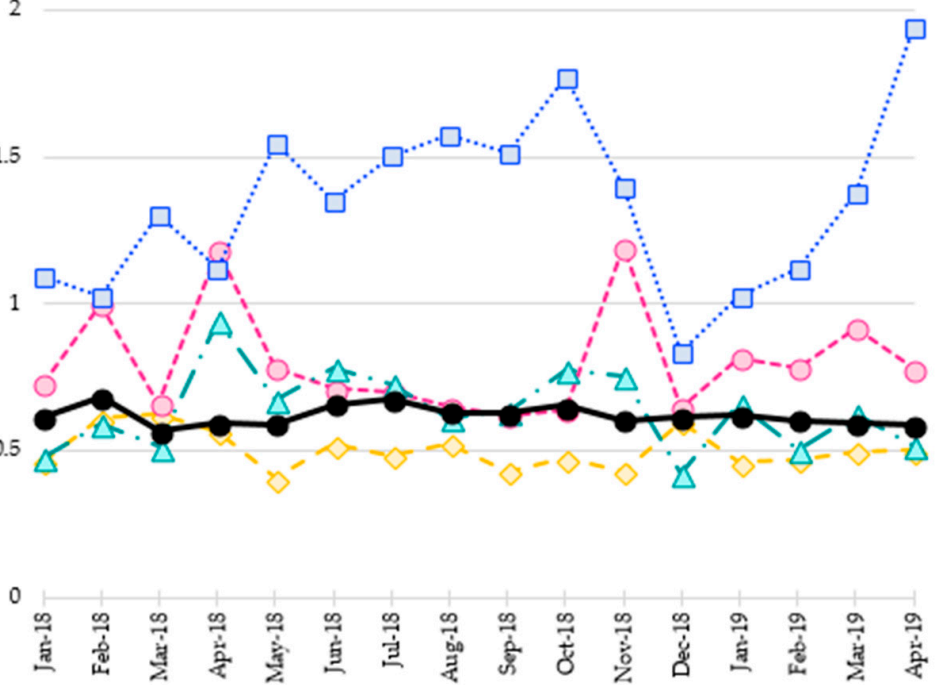

- Broad Spectrum Antibacterial Agents Predominantly Used for Hospital-Onset Infections (ADULT ICU)

- - Broad Spectrum Antibacterial Agents Predominantly Used for Community-Aoquired Infections (ADULT ICU)

... Narrow Spectrum Beta-Lactam Agents (ADULT ICU)

$\rightarrow$. Broad Spectrum Antibacterial Agents Predominantly Used for Gram-positive Infections (ADULT ICU)

—All Antibacterial Agents (ADULT FACILITY-WIDE)

(A)

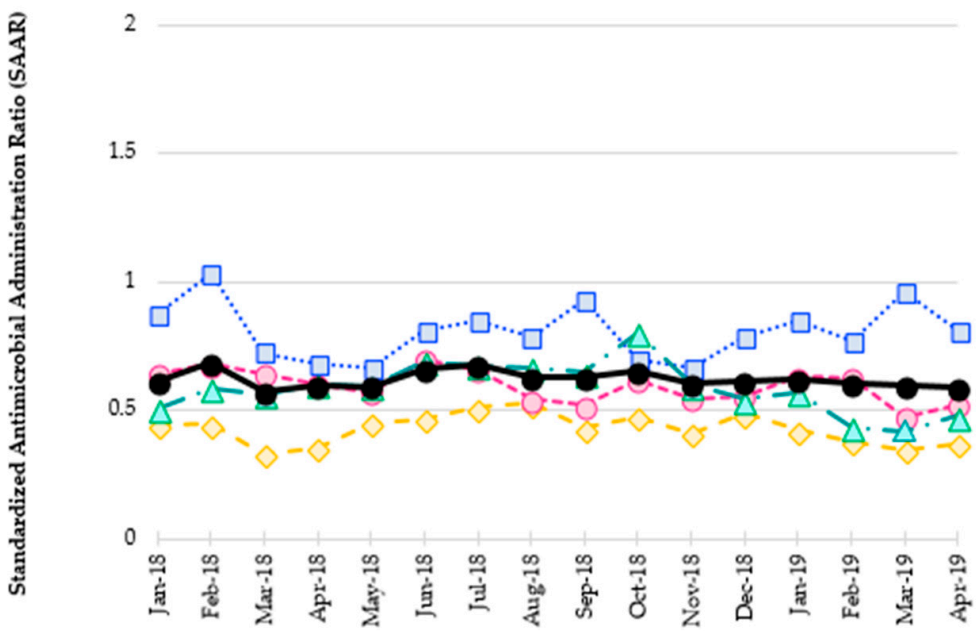

- Broad Spectrum Antibacterial Agents Predominantly Used for Hospital-Onset Infections (ADULT WARDS)

- $\infty$ - Broad Spectrum Antibacterial Agents Predominantly Used for Community-A Aquired Infections (ADULT WARDS)

.... Narrow Spectrum Beta-Lactam Agents (ADULT WARDS)

$\rightarrow$ Broad Spectrum Antibacterial Agents Predominantly Used for Gram-positive Infections (ADULT WARDS)

$\longrightarrow$ All Antibacterial Agents (ADULT FACILITY-WIDE)

(B)

Figure 1. (A) Standardized Antimicrobial Administration Ratio (SAAR) report for all and select categories of antibacterial agents in adult intensive care units (ICUs) at a community-teaching hospital. (B) Standardized Antimicrobial Administration Ratio (SAAR) report for all and select categories of antibacterial agents at adult wards at a community-teaching hospital. 


\subsection{Antimicrobial Resistance (AR) Option}

Facilities reporting to the AR option will receive a facility-wide antibiogram that can be stratified by source, time period, and specific antibiotics or organisms [80]. Participating facilities will also get a line list generated for all AR events including items such as date of birth, gender, specimen type, and organism. The benefits of this option for tracking the success of an ASP is similar to tracking MRSA, ESBLE, CRE, and resistance among $P$. aeruginosa and A. baumannii isolates. While short-term changes may be difficult to visualize, it may be possible to show long-term success. It also allows for benchmarking with other similar institutions. Both the AU and AR modules within the NHSN are promising ASP metrics with different potential uses.

\section{Discussion}

Historically, direct measurement of antimicrobial use was not feasible for most institutions; thus, surrogate metrics such as HO-CDI incidence and cost were derived. The assumption was that higher incidence rates of HO-CDI and infections due to MDR bacteria reflected excessive antimicrobial use of broad-spectrum agents at an institution. However, in the era of electronic medical records and progressive advancements of healthcare informatics, direct measurement of antimicrobial use has become a reality. CDC/NHSN module for reporting antimicrobial use and antimicrobial resistance provides the tools for direct measurements of ASP daily work and overall performance. Despite some initial hurdles, hospitals and ASPs are both determined to make this breakthrough advancement in the field of antimicrobial stewardship by improving ASP metrics. Adjustments of antimicrobial use by quality of care and institutional microbiological burden will evolve with time. Practical adjustment formulas, which demonstrate validity and generalizability across a broad mix of hospital types and geographical locations, will prove most useful.

ASP metrics may be classified into direct measures of ASP performance and global metrics for overall healthcare system evaluation. Antimicrobial use of broad-spectrum agents represents the primary direct ASP metric. Secondary direct metrics include incidence rate of CRE and antimicrobial resistance of predominantly hospital-onset pathogens, such as P. aeruginosa and A. baumannii (Table 4).

Table 4. Direct antimicrobial stewardship metrics.

\begin{tabular}{|c|c|}
\hline ASP Metrics & Description \\
\hline $\begin{array}{l}\text { Antimicrobial use of broad-spectrum agents: } \\
\text { Antipseudomonal beta-lactams } \\
\text { Carbapenems } \\
\text { Anti-MRSA agents } \\
\text { Anti-VRE agents }\end{array}$ & $\begin{array}{l}\text { - } \quad \text { Most direct measure of ASP performance } \\
\text { Evaluates effectiveness of ASP interventions } \\
\text { (e.g., syndrome-specific, prospective audit and feedback, } \\
\text { de-escalation of therapy) } \\
\text { - } \quad \text { Measures both empirical and definitive therapy } \\
\text { - Adjustments by quantity (facility size, patient population, } \\
\text { or microbiological burden) and quality (appropriateness of } \\
\text { therapy) at each healthcare facility are possible }\end{array}$ \\
\hline $\begin{array}{l}\text { Antimicrobial resistance of predominantly } \\
\text { hospital-onset bacteria: } \\
\text { Pseudomonas aeruginosa } \\
\text { Acinetobacter baumannii }\end{array}$ & $\begin{array}{l}\text { - Antimicrobial resistance of hospital-onset bacteria is associated } \\
\text { with use of broad-spectrum antimicrobials at each institution } \\
\text { Antimicrobial resistance may also be influenced by referrals, } \\
\text { especially at tertiary care centers } \\
\text { Patient-to-patient transmission of MDR bacteria may be reduced } \\
\text { by effective infection prevention and control methods }\end{array}$ \\
\hline Incidence rate of CRE & $\begin{array}{l}\text { - Excessive use of carbapenems and other broad-spectrum } \\
\text { antimicrobials increases risk of CRE infections or colonization } \\
\text { - CRE rates may be influenced by transfers from other hospitals or } \\
\text { skilled nursing facilities } \\
\text { - Infection prevention and control programs are essential for } \\
\text { reducing transmission of CRE in healthcare facilities }\end{array}$ \\
\hline
\end{tabular}

Note: ASP: antimicrobial stewardship programs; MRSA: methicillin-resistant Staphylococcus aureus; VRE: vancomycin-resistant Enterococcus species; MDR: multi-drug resistant; CRE: carbapenem-resistant Enterobacteriaceae. 
In addition to these direct metrics, global metrics, including rates of CDI, MRSA, ESBLE, as well as cost of healthcare, should continue to be used in order to evaluate overall performance of healthcare systems (Table 5).

Table 5. Global metrics of overall healthcare system performance.

\begin{tabular}{|c|c|}
\hline Global Metrics & Description \\
\hline $\begin{array}{l}\text { Incidence rate of hospital-onset } \\
\text { Clostridioides difficile infection }\end{array}$ & $\begin{array}{l}\text { - Indirect assessment of quantity and spectrum of AU in } \\
\text { healthcare facilities } \\
\text { Tool for evaluation of IPCPs, clinical decision support programs, } \\
\text { laboratory, and diagnostic stewardship }\end{array}$ \\
\hline $\begin{array}{l}\text { Incidence rate of ESBLE infections } \\
\text { or colonization }\end{array}$ & $\begin{array}{l}\text { - } \quad \text { ESBLE predominantly cause community-onset infections in North } \\
\text { America and Europe } \\
\text { - } \quad \text { Better metric for ambulatory ASPs and IPCPs than inpatient ASPs } \\
\text { - } \quad \text { Rates are influenced by prior colonization }\end{array}$ \\
\hline $\begin{array}{l}\text { Incidence rate of MRSA infections } \\
\text { or colonization }\end{array}$ & $\begin{array}{l}\text { - } \quad \text { MRSA has emerged as community-onset bacteria as well } \\
\text { - } \\
\text { - }\end{array}$ \\
\hline $\begin{array}{l}\text { Sepsis or bloodstream infection } \\
\text { case-fatality rate }\end{array}$ & $\begin{array}{l}\text { - Evaluates clinical, diagnostic, and interventional critical care skills; } \\
\text { clinical decision support programs; and laboratory diagnostics, } \\
\text { including microbiology } \\
\text { - ASPs may influence only one of many variables that determine } \\
\text { outcome, that is, empirical antimicrobial therapy through } \\
\text { institutional management guidelines and other interventions }\end{array}$ \\
\hline Cost of healthcare & $\begin{array}{l}\text { - Antimicrobial cost is a fraction of total healthcare cost } \\
\text { - ASPs may indirectly contribute to reduction in healthcare cost by } \\
\text { reducing length of hospital stay through selection of appropriate } \\
\text { empirical antimicrobial therapy and reducing risk of antimicrobial } \\
\text { adverse events such as acute kidney injury and C. difficile infection }\end{array}$ \\
\hline
\end{tabular}

\section{Conclusions}

In this new era of antimicrobial stewardship, direct measurement of ASP performance is feasible and preferable. Antimicrobial use within an institution represents the most direct and specific antimicrobial stewardship metric for hospital-based ASPs. Antimicrobial resistance of predominantly hospital-onset bacteria, such as P. aeruginosa and A. baumannii, represents a secondary antimicrobial stewardship metric. Participation of US hospitals in currently available CDC/NHSN modules for antimicrobial use and resistance is highly encouraged and represents a valuable step to improve antimicrobial stewardship at the national level. Novel stewardship metrics presented in this review allow adjustment of antimicrobial use by microbiological burden and quality of care as measured by appropriateness of empirical antimicrobial therapy at each institution. This enhances the antimicrobial stewardship mission in improving both the quantity and quality of patient care.

Author Contributions: Conceptualization, M.N.A.-H., H.R.W., P.B.B., and J.J.; Methodology, M.N.A.-H., H.R.W., P.B.B., and J.A.J.; Writing-original draft preparation, M.N.A.-H. and H.R.W.; writing-review and editing, M.N.A.-H., H.R.W., P.B.B., and J.A.J.; Visualization, M.N.A.-H., H.R.W., P.B.B., and J.A.J.; Supervision, M.N.A.-H., P.B.B., and J.A.J.; Project administration, M.N.A.-H.

Funding: This research received no external funding.

Acknowledgments: The authors thank Joseph Kohn and Prisma Health-Midlands Antimicrobial Stewardship and Support Team in South Carolina, USA for providing antimicrobial use data for demonstration in figures and for their valuable input in this narrative review. 
Conflicts of Interest: H.R.W.: Speaker, ALK Abello. P.B.B.: Advisory board member, Melinta Therapeutics; Program content developer and speaker, FreeCE.com; Grant support, ALK Abello. M.N.A.-H. and J.A.J.: No conflicts.

\section{Abbreviations}

$\mathrm{ASP}=$ antimicrobial stewardship program; $\mathrm{AR}=$ antimicrobial resistance; $\mathrm{AU}=$ antimicrobial use; $\mathrm{CDC}=\mathrm{Centers}$ for Disease Control and Prevention; CDI = Clostridioides difficile infection; $\mathrm{CRE}=$ carbapenem-resistant Enterobacteriaceae; $\mathrm{DDD}=$ defined daily dose; DOT = days of therapy; ESBLE = extended-spectrum beta-lactamase-producing Enterobacteriaceae; HO-CDI = hospital-onset Clostridioides difficile infection; ICU = intensive care unit; MDR = multidrug-resistant; MRSA = methicillin-resistant Staphylococcus aureus; NHSN = National Healthcare Safety Network; SAAR=Standardized Antimicrobial Administration Ratio

\section{References}

1. Barlam, T.F.; Cosgrove, S.E.; Abbo, L.M.; MacDougall, C.; Schuetz, A.N.; Septimus, E.J.; Srinivasan, A.; Dellit, T.H.; Falck-Ytter, Y.T.; Fishman, N.O.; et al. Implementing an antibiotic stewardship program: Guidelines by the Infectious Diseases Society of America and the Society for Healthcare Epidemiology of America. Clin. Infect. Dis. 2016, 62, e51-e77. [CrossRef] [PubMed]

2. Moehring, R.W.; Anderson, D.J.; Cochran, R.L.; Hicks, L.A.; Srinivasan, A.; Dodds Ashley, E.S. Structured Taskforce of Experts Working at Reliable Standards for Stewardship (STEWARDS) Panel. Expert consensus on metrics to assess the impact of patient-level antimicrobial stewardship interventions in acute-care settings. Clin. Infect. Dis. 2017, 64, 377-383. [CrossRef] [PubMed]

3. Science, M.; Timberlake, K.; Morris, A.; Read, S.; Le Saux, N. Groupe Antibiothérapie en Pédiatrie Canada Alliance for Stewardship of Antimicrobials in Pediatrics (GAP Can ASAP); Quality metrics for antimicrobial stewardship programs; Pediatrics: Elk Grove, IL, USA, 2019; p. 143.

4. Nagel, J.L.; Stevenson, J.G.; Eiland, E.H.; Kaye, K.S. Demonstrating the value of antimicrobial stewardship programs to hospital administrators. Clin. Infect. Dis. 2014, 59 (Suppl. 3), S146-S153. [CrossRef] [PubMed]

5. Brotherton, A.L. Metrics of antimicrobial stewardship programs. Med. Clin. N. Am. 2018, 102, 965-976. [CrossRef] [PubMed]

6. Bennett, N.; Schulz, L.; Boyd, S.; Newland, J.G. Understanding inpatient antimicrobial stewardship metrics. Am. J. Health Syst. Pharm. 2018, 75, 230-238. [CrossRef] [PubMed]

7. Tumbarello, M.; Trecarichi, E.M.; Bassetti, M.; De Rosa, F.G.; Spanu, T.; Di Meco, E.; Losito, A.R.; Parisini, A.; Pagani, N.; Cauda, R. Identifying patients harboring extended-spectrum-beta-lactamase-producing Enterobacteriaceae on hospital admission: Derivation and validation of a scoring system. Antimicrob. Agents Chemother. 2011, 55, 3485-3490. [CrossRef] [PubMed]

8. Augustine, M.R.; Testerman, T.L.; Justo, J.A.; Bookstaver, P.B.; Kohn, J.; Albrecht, H.; Al-Hasan, M.N. Clinical risk score for prediction of extended-spectrum beta-lactamase-producing Enterobacteriaceae in bloodstream isolates. Infect. Control Hosp. Epidemiol. 2017, 38, 266-272. [CrossRef]

9. Khanna, S.; Pardi, D.S.; Aronson, S.L.; Kammer, P.P.; Orenstein, R.; St Sauver, J.L.; Zinsmeister, A.R. The epidemiology of community-acquired Clostridium difficile infection: A population-based study. Am. J. Gastroenterol. 2012, 107, 89-95. [CrossRef]

10. Lambert, P.J.; Dyck, M.; Thompson, L.H.; Hammond, G.W. Population-based surveillance of Clostridium difficile infection in Manitoba, Canada, by using interim surveillance definitions. Infect. Control Hosp. Epidemiol. 2009, 30, 945-951. [CrossRef]

11. Pitout, J.D.; Hanson, N.D.; Church, D.L.; Laupland, K.B. Population-based laboratory surveillance for Escherichia coli-producing extended-spectrum beta-lactamases: Importance of community isolates with blaCTX-M genes. Clin. Infect. Dis. 2004, 38, 1736-1741. [CrossRef]

12. Thaden, J.T.; Fowler, V.G.; Sexton, D.J.; Anderson, D.J. Increasing incidence of extended-spectrum beta-lactamase-producing Escherichia coli in community hospitals throughout the Southeastern United States. Infect. Control Hosp. Epidemiol. 2016, 37, 49-54. [CrossRef] [PubMed]

13. Global Priority List of Antibiotic-Resistant Bacteria to Guide Research, Discovery, and Development of New Antibiotics. World Health Organization, 2017. Available online: https://www.who.int/medicines/ publications/global-priority-list-antibiotic-resistant-bacteria/en/ (accessed on 30 June 2019). 
14. Karino, S.; Kaye, K.S.; Navalkele, B.; Nishan, B.; Salim, M.; Solanki, S.; Pervaiz, A.; Tashtoush, N.; Shaikh, H.; Koppula, S.; et al. Epidemiology of acute kidney injury among patients receiving concomitant vancomycin and piperacillin-tazobactam: Opportunities for antimicrobial stewardship. Antimicrob. Agents Chemother. 2016, 60, 3743-3750. [CrossRef] [PubMed]

15. Hammond, D.A.; Smith, M.N.; Li, C.; Hayes, S.M.; Lusardi, K.; Bookstaver, P.B. Systematic review and meta-analysis of acute kidney injury associated with concomitant vancomycin and piperacillin/tazobactam. Clin. Infect. Dis. 2017, 64, 666-674. [CrossRef] [PubMed]

16. Piacenti, F.J.; Leuthner, K.D. Antimicrobial stewardship and Clostridium difficile-associated diarrhea. J. Pharm. Pract. 2013, 26, 506-513. [CrossRef] [PubMed]

17. Longtin, Y.; Trottier, S.; Brochu, G.; Paquet-Bolduc, B.; Garenc, C.; Loungnarath, V.; Beaulieu, C.; Goulet, D.; Longtin, J. Impact of the type of diagnostic assay on Clostridium difficile infection and complication rates in a mandatory reporting program. Clin. Infect. Dis. 2013, 56, 67-73. [CrossRef] [PubMed]

18. Grein, J.D.; Ochner, M.; Hoang, H.; Jin, A.; Morgan, M.A.; Murthy, A.R. Comparison of testing approaches for Clostridium difficile infection at a large community hospital. Clin. Microbiol. Infect. 2014, 20, 65-69. [CrossRef] [PubMed]

19. Kelly, S.G.; Yarrington, M.; Zembower, T.R.; Sutton, S.H.; Silkaitis, C.; Postelnick, M.; Mikolajczak, A.; Bolon, M.K. Inappropriate Clostridium difficile testing and consequent overtreatment and inaccurate publicly reported metrics. Infect. Control Hosp. Epidemiol. 2016, 37, 1395-1400. [CrossRef]

20. Graber, C.J. Clostridium difficile infection: Stewardship's lowest hanging fruit? Lancet Infect. Dis. 2017, 17, 123-124. [CrossRef]

21. Al-Hasan, M.N.; Wilson, J.W.; Lahr, B.D.; Thomsen, K.M.; Eckel-Passow, J.E.; Vetter, E.A.; Tleyjeh, I.M.; Baddour, L.M. Beta-lactam and fluoroquinolone combination antibiotic therapy for bacteremia caused by gram-negative bacilli. Antimicrob. Agents Chemother. 2009, 53, 1386-1394. [CrossRef]

22. Seddon, M.M.; Bookstaver, P.B.; Justo, J.A.; Kohn, J.; Rac, H.; Haggard, E.; Mediwala, K.N.; Dash, S.; Al-Hasan, M.N. Role of early de-escalation of antimicrobial therapy on risk of Clostridioides difficile infection following Enterobacteriaceae bloodstream infections. Clin. Infect. Dis. 2019, 69, 414-420. [CrossRef]

23. Tucker, K.; Lashkova, L.; Flemming, T.; Justo, J.; Kohn, J.; Al-Hasan, M.N.; Sanasi, K.; Bookstaver, P.B. Impact of antimicrobial stewardship initiatives on carbapenem utilization and antimicrobial resistance. In Proceedings of the 55th Interscience Conference on Antimicrobial Agents and Chemotherapy, San Diego, CA, USA, 17-21 September 2015. Abstract \#2243.

24. Palacios-Baena, Z.R.; Delgado-Valverde, M.; Valiente Méndez, A.; Almirante, B.; Gómez-Zorrilla, S.; Borrell, N.; Corzo, J.E.; Gurguí, M.; de la Calle, C.; García-Álvarez, L.; et al. Impact of de-escalation on prognosis of patients with bacteraemia due to Enterobacteriaceae: A post-hoc analysis from a multicenter prospective cohort. Clin. Infect. Dis. 2018. [CrossRef] [PubMed]

25. Tariq, R.; Singh, S.; Gupta, A.; Pardi, D.S.; Khanna, S. Association of gastric acid suppression with recurrent Clostridium difficile infection: A systematic review and meta-analysis. JAMA Intern. Med. 2017, 177, 784-791. [CrossRef] [PubMed]

26. Thomas, C.; Stevenson, M.; Riley, T.V. Antibiotics and hospital-acquired Clostridium difficile-associated diarrhoea: A systematic review. J. Antimicrob. Chemother. 2003, 51, 1339-1350. [CrossRef] [PubMed]

27. Brown, K.A.; Khanafer, N.; Daneman, N.; Fisman, D.N. Meta-analysis of antibiotics and the risk of community-associated Clostridium difficile infection. Antimicrob. Agents Chemother. 2013, 57, 2326-2332. [CrossRef]

28. Pagels, C.M.; McCreary, E.K.; Rose, W.E.; Dodds Ashley, E.S.; Bookstaver, P.B.; Dilworth, T.J. Designing antimicrobial stewardship initiatives to enhance scientific dissemination. J. Am. Coll. Clin. Pharm. 2019, 1-7. [CrossRef]

29. McFarland, L.V.; Surawicz, C.M.; Stamm, W.E. Risk factors for Clostridium difficile carriage and, C. difficileassociated diarrhea in a cohort of hospitalized patients. J. Infect. Dis. 1990, 162, 678-684. [CrossRef] [PubMed]

30. Lawes, T.; Lopez-Lozano, J.M.; Nebot, C.A.; Macartney, G.; Subbarao-Sharma, R.; Wares, K.D.; Sinclair, C.; Gould, I.M. Effect of a national 4C antibiotic stewardship intervention on the clinical and molecular epidemiology of Clostridium difficile infections in a region of Scotland: A non-linear time-series analysis. Lancet Infect. Dis. 2017, 17, 194-206. [CrossRef]

31. Harris, A.D.; Sbarra, A.N.; Leekha, S.; Jackson, S.S.; Johnson, J.K.; Pineles, L.; Thom, K.A. Electronically available comorbid conditions for risk prediction of healthcare-associated Clostridium difficile infection. Infect. Control Hosp. Epidemiol. 2018, 39, 297-301. [CrossRef] 
32. Al-Hasan, M.N.; Lahr, B.D.; Eckel-Passow, J.E.; Baddour, L.M. Antimicrobial resistance trends of Escherichia coli bloodstream isolates: A population-based study, 1998-2007. J. Antimicrob. Chemother. 2009, 64, 169-174. [CrossRef]

33. Waltner-Toews, R.I.; Paterson, D.L.; Qureshi, Z.A.; Sidjabat, H.E.; Adams-Haduch, J.M.; Shutt, K.A.; Jones, M.; Tian, G.B.; Pasculle, A.W.; Doi, Y. Clinical characteristics of bloodstream infections due to ampicillin-sulbactam-resistant, non-extended-spectrum-beta-lactamase-producing Escherichia coli and the role of TEM-1 hyperproduction. Antimicrob. Agents Chemother. 2011, 55, 495-501. [CrossRef]

34. Baggs, J.; Fridkin, S.K.; Pollack, L.A.; Srinivasan, A.; Jernigan, J.A. Estimating National trends in inpatient antibiotic use among US hospitals from 2006 to 2012. JAMA Intern. Med. 2016, 176, 1639-1648. [CrossRef]

35. Logan, L.K.; Gandra, S.; Mandal, S.; Klein, E.Y.; Levinson, J.; Weinstein, R.A.; Laxminarayan, R. Prevention Epicenters Program, US Centers for Disease Control and Prevention. Multidrug- and carbapenem-resistant Pseudomonas aeruginosa in children, United States, 1999-2012. J. Pediatr. Infect. Dis. Soc. 2017, 6, 352-359.

36. Knothe, H.; Shah, P.; Krcmery, V.; Antal, M.; Mitsuhashi, S. Transferable resistance to cefotaxime, cefoxitin, cefamandole and cefuroxime in clinical isolates of Klebsiella pneumoniae and Serratia marcescens. Infection 1983, 11, 315-317. [CrossRef]

37. Rodriguez-Bano, J.; Navarro, M.D.; Romero, L.; Martínez-Martínez, L.; Muniain, M.A.; Perea, E.J.; Pérez-Cano, R.; Pascual, A. Epidemiology and clinical features of infections caused by extended-spectrum beta-lactamase-producing Escherichia coli in nonhospitalized patients. J. Clin. Microbiol. 2004, 42, 1089-1094. [CrossRef]

38. Rottier, W.C.; Bamberg, Y.R.; Dorigo-Zetsma, J.W.; van der Linden, P.D.; Ammerlaan, H.S.; Bonten, M.J. Predictive value of prior colonization and antibiotic use for third-generation cephalosporin-resistant enterobacteriaceae bacteremia in patients with sepsis. Clin. Infect. Dis. 2015, 60, 1622-1630. [CrossRef]

39. Morgan, D.J.; Meddings, J.; Saint, S.; Lautenbach, E.; Shardell, M.; Anderson, D.; Milstone, A.M.; Drees, M.; Pineles, L.; Safdar, N.; et al. SHEA Research Network. Does nonpayment for hospital-acquired catheter-associated urinary tract infections lead to overtesting and increased antimicrobial prescribing? Clin. Infect. Dis. 2012, 55, 923-929. [CrossRef]

40. Lawes, T.; Lopez-Lozano, J.M.; Nebot, C.A.; Macartney, G.; Subbarao-Sharma, R.; Dare, C.R.; Wares, K.D.; Gould, I.M. Effects of national antibiotic stewardship and infection control strategies on hospital-associated and community-associated meticillin-resistant Staphylococcus aureus infections across a region of Scotland: A non-linear time-series study. Lancet Infect. Dis. 2015, 15, 1438-1449. [CrossRef]

41. Jain, R.; Kralovic, S.M.; Evans, M.E.; Ambrose, M.; Simbartl, L.A.; Obrosky, D.S.; Render, M.L.; Freyberg, R.W.; Jernigan, J.A.; Muder, R.R.; et al. Veterans Affairs initiative to prevent methicillin-resistant Staphylococcus aureus infections. N. Engl. J. Med. 2011, 364, 1419-1430. [CrossRef]

42. Klein, E.Y.; Mojica, N.; Jiang, W.; Cosgrove, S.E.; Septimus, E.; Morgan, D.J.; Laxminarayan, R. Trends in methicillin-resistant Staphylococcus aureus hospitalizations in the United States, 2010-2014. Clin. Infect. Dis. 2017, 65, 1921-1923. [CrossRef]

43. Kourtis, A.P.; Hatfield, K.; Baggs, J.; Mu, Y.; See, I.; Epson, E.; Nadle, J.; Kainer, M.A.; Dumyati, G.; Petit, S.; et al. Vital signs: Epidemiology and recent trends in methicillin-resistant and in methicillin-susceptible Staphylococcus aureus bloodstream infections-United States. MMWR Morb. Mortal. Wkly. Rep. 2019, 68, 214-219. [CrossRef]

44. FDA Updates Warnings for Fluoroquinolone Antibiotics. Available online: http://www.fda.gov/NewsEvents/ Newsroom/PressAnnouncements/ucm513183.htm (accessed on 4 June 2019).

45. Orsi, G.B.; Bencardino, A.; Vena, A.; Carattoli, A.; Venditti, C.; Falcone, M.; Giordano, A.; Venditti, M. Patient risk factors for outer membrane permeability and KPC-producing carbapenem-resistant Klebsiella pneumoniae isolation: Results of a double case-control study. Infection 2013, 41, 61-67. [CrossRef]

46. Al-Hasan, M.N.; Wilson, J.W.; Lahr, B.D.; Eckel-Passow, J.E.; Baddour, L.M. Incidence of Pseudomonas aeruginosa bacteremia: A population-based study. Am. J. Med. 2008, 121, 702-708. [CrossRef]

47. Gransden, W.R.; Leibovici, L.; Eykyn, S.J.; Pitlik, S.D.; Samra, Z.; Konisberger, H.; Drucker, M.; Phillips, I. Risk factors and a clinical index for diagnosis of Pseudomonas aeruginosa bacteremia. Clin. Microbiol. Infect. 1995, 1, 119-123. [CrossRef]

48. Hammer, K.L.; Justo, J.A.; Bookstaver, P.B.; Kohn, J.; Albrecht, H.; Al-Hasan, M.N. Differential effect of prior beta-lactams and fluoroquinolones on risk of bloodstream infections secondary to Pseudomonas aeruginosa. Diagn. Microbiol. Infect. Dis. 2017, 87, 87-91. [CrossRef] 
49. Cheong, H.S.; Kang, C.I.; Wi, Y.M.; Kim, E.S.; Lee, J.S.; Ko, K.S.; Chung, D.R.; Lee, N.Y.; Song, J.H.; Peck, K.R. Clinical significance and predictors of community-onset Pseudomonas aeruginosa bacteremia. Am. J. Med. 2008, 121, 709-714. [CrossRef]

50. Schechner, V.; Nobre, V.; Kaye, K.S.; Leshno, M.; Giladi, M.; Rohner, P.; Harbarth, S.; Anderson, D.J.; Karchmer, A.W.; Schwaber, M.J.; et al. Gram-negative bacteremia upon hospital admission: When should Pseudomonas aeruginosa be suspected? Clin. Infect. Dis. 2009, 48, 580-586. [CrossRef]

51. Decraene, V.; Ghebrehewet, S.; Dardamissis, E.; Huyton, R.; Mortimer, K.; Wilkinson, D.; Shokrollahi, K.; Singleton, S.; Patel, B.; Turton, J.; et al. An outbreak of multidrug-resistant Pseudomonas aeruginosa in a burns service in the North of England: Challenges of infection prevention and control in a complex setting. J. Hosp. Infect. 2018, 100, e239-e245. [CrossRef]

52. Milan, A.; Furlanis, L.; Cian, F.; Bressan, R.; Luzzati, R.; Lagatolla, C.; Deiana, M.L.; Knezevich, A.; Tonin, E.; Dolzani, L. Epidemic dissemination of a carbapenem-resistant Acinetobacter baumannii clone carrying armA two years after its first isolation in an Italian hospital. Microb. Drug Resist. 2016, 22, 668-674. [CrossRef]

53. Paramythiotou, E.; Lucet, J.C.; Timsit, J.F.; Vanjak, D.; Paugam-Burtz, C.; Trouillet, J.L.; Belloc, S.; Kassis, N.; Karabinis, A.; Andremont, A. Acquisition of multidrug-resistant Pseudomonas aeruginosa in patients in intensive care units: Role of antibiotics with antipseudomonal activity. Clin. Infect. Dis. 2004, 38, 670-677. [CrossRef]

54. Montero, M.; Sala, M.; Riu, M.; Belvis, F.; Salvado, M.; Grau, S.; Horcajada, J.P.; Alvarez-Lerma, F.; Terradas, R.; Orozco-Levi, M.; et al. Risk factors for multidrug-resistant Pseudomonas aeruginosa acquisition. Impact of antibiotic use in a double case-control study. Eur. J. Clin. Microbiol. Infect. Dis. 2010, 29, 335-339. [CrossRef]

55. Nakamura, A.; Miyake, K.; Misawa, S.; Kuno, Y.; Horii, T.; Kondo, S.; Tabe, Y.; Ohsaka, A. Meropenem as predictive risk factor for isolation of multidrug-resistant Pseudomonas aeruginosa. J. Hosp. Infect. 2013, 83, 153-155. [CrossRef]

56. Cobos-Trigueros, N.; Sole, M.; Castro, P.; Torres, J.L.; Hernández, C.; Rinaudo, M.; Fernández, S.; Soriano, Á.; Nicolás, J.M.; Mensa, J.; et al. Acquisition of Pseudomonas aeruginosa and its resistance phenotypes in critically ill medical patients: Role of colonization pressure and antibiotic exposure. Crit. Care 2015, 19, 218. [CrossRef]

57. Al-Jaghbeer, M.J.; Justo, J.A.; Owens, W.; Kohn, J.; Bookstaver, P.B.; Hucks, J.; Al-Hasan, M.N. Risk factors for pneumonia due to beta-lactam-susceptible and beta-lactam-resistant Pseudomonas aeruginosa: A case-case-control study. Infection 2018, 46, 487-494. [CrossRef]

58. Cain, S.E.; Kohn, J.; Bookstaver, P.B.; Albrecht, H.; Al-Hasan, M.N. Stratification of the impact of inappropriate empirical antimicrobial therapy for Gram-negative bloodstream infections by predicted prognosis. Antimicrob. Agents Chemother. 2015, 59, 245-250. [CrossRef]

59. Retamar, P.; Portillo, M.M.; Lopez-Prieto, M.D.; Rodríguez-López, F.; de Cueto, M.; García, M.V.; Gómez, M.J.; Del Arco, A.; Muñoz, A.; Sánchez-Porto, A.; et al. SAEI/SAMPAC Bacteremia Group. Impact of inadequate empirical therapy on the mortality of patients with bloodstream infections: A propensity score-based analysis. Antimicrob. Agents Chemother. 2012, 56, 472-478. [CrossRef]

60. Al-Hasan, M.N.; Rac, H. Transition from intravenous to oral antimicrobial therapy in patients with uncomplicated and complicated bloodstream infections. Clin. Microbiol. Infect. 2019. [CrossRef]

61. Paul, M.; Shani, V.; Muchtar, E.; Kariv, G.; Robenshtok, E.; Leibovici, L. Systematic review and meta-analysis of the efficacy of appropriate empiric antibiotic therapy for sepsis. Antimicrob. Agents Chemother. 2010, 54, 4851-4863. [CrossRef]

62. Shorr, A.F.; Micek, S.T.; Welch, E.C.; Doherty, J.A.; Reichley, R.M.; Kollef, M.H. Inappropriate antibiotic therapy in Gram-negative sepsis increases hospital length of stay. Crit. Care Med. 2011, 39, 46-51. [CrossRef]

63. Battle, S.E.; Bookstaver, P.B.; Justo, J.A.; Kohn, J.; Albrecht, H.; Al-Hasan, M.N. Association between inappropriate empirical antimicrobial therapy and hospital length of stay in Gram-negative bloodstream infections: Stratification by prognosis. J. Antimicrob. Chemother. 2017, 72, 299-304. [CrossRef]

64. Sogaard, M.; Norgaard, M.; Dethlefsen, C.; Schonheyder, H.C. Temporal changes in the incidence and 30-day mortality associated with bacteremia in hospitalized patients from 1992 through 2006: A population-based cohort study. Clin. Infect. Dis. 2011, 52, 61-69. [CrossRef]

65. Nimmich, E.B.; Bookstaver, P.B.; Kohn, J.; Justo, J.A.; Hammer, K.L.; Albrecht, H.; Al-Hasan, M.N. Development of Institutional Guidelines for Management of Gram-Negative Bloodstream Infections: Incorporating Local Evidence. Hosp. Pharm. 2017, 52, 691-697. [CrossRef] 
66. Bookstaver, P.B.; Nimmich, E.B.; Smith, T.J.; Justo, J.A.; Kohn, J.; Hammer, K.L.; Troficanto, C.; Albrecht, H.A.; Al-Hasan, M.N. Cumulative effect of an antimicrobial stewardship and rapid diagnostic testing bundle on early streamlining of antimicrobial therapy in Gram-negative bloodstream infections. Antimicrob. Agents Chemother. 2017, 61, e00189-17. [CrossRef]

67. Al-Hasan, M.N.; Lahr, B.D.; Eckel-Passow, J.E.; Baddour, L.M. Predictive scoring model of mortality in Gram-negative bloodstream infection. Clin. Microbiol. Infect. 2013, 19, 948-954. [CrossRef]

68. Al-Hasan, M.N.; Juhn, Y.J.; Bang, D.W.; Yang, H.J.; Baddour, L.M. External validation of bloodstream infection mortality risk score in a population-based cohort. Clin. Microbiol. Infect. 2014, 20, 886-891. [CrossRef]

69. Huang, A.M.; Newton, D.; Kunapuli, A.; Gandhi, T.N.; Washer, L.L.; Isip, J.; Collins, C.D.; Nagel, J.L. Impact of rapid organism identification via matrix-assisted laser desorption/ionization time-of-flight combined with antimicrobial stewardship team intervention in adult patients with bacteremia and candidemia. Clin. Infect. Dis. 2013, 57, 1237-1245. [CrossRef]

70. MacVane, S.H.; Nolte, F.S. Benefits of adding a rapid PCR-based blood culture identification panel to an established antimicrobial stewardship program. J. Clin. Microbiol. 2016, 54, 2455-2463. [CrossRef]

71. Banerjee, R.; Teng, C.B.; Cunningham, S.A.; Ihde, S.M.; Steckelberg, J.M.; Moriarty, J.P.; Shah, N.D.; Mandrekar, J.N.; Patel, R. Randomized trial of rapid multiplex polymerase chain reaction-based blood culture identification and susceptibility testing. Clin. Infect. Dis. 2015, 61, 1071-1080. [CrossRef]

72. Mediwala, K.N.; Kohn, J.E.; Bookstaver, P.B.; Justo, J.A.; Rac, H.; Tucker, K.; Lashkova, L.; Dash, S.; Al-Hasan, M.N. Syndrome-specific versus prospective audit and feedback interventions for reducing use of broad-spectrum antimicrobial agents. Am. J. Infect. Control 2019. [CrossRef]

73. Sick, A.C.; Lehmann, C.U.; Tamma, P.D.; Lee, C.K.; Agwu, A.L. Sustained savings from a longitudinal cost analysis of an internet-based preapproval antimicrobial stewardship program. Infect. Control Hosp. Epidemiol. 2013, 34, 573-580. [CrossRef]

74. Beardsley, J.R.; Williamson, J.C.; Johnson, J.W.; Luther, V.P.; Wrenn, R.H.; Ohl, C.C. Show me the money: Long-term financial impact of an antimicrobial stewardship program. Infect. Control Hosp. Epidemiol. 2012, 33, 398-400. [CrossRef]

75. Ozkurt, Z.; Erol, S.; Kadanali, A.; Ertek, M.; Ozden, K.; Tasyaran, M.A. Changes in antibiotic use, cost and consumption after an antibiotic restriction policy applied by infectious disease specialists. Jpn. J. Infect. Dis. 2005, 58, 338-343.

76. Akpan, M.R.; Ahmad, R.; Shebl, N.A.; Ashiru-Oredope, D. A review of quality measures for assessing the impact of antimicrobial stewardship programs in hospitals. Antibiotics 2016, 5, 5. [CrossRef]

77. Bartlett, J.M.; Siola, P.L. Implementation and first-year results of an antimicrobial stewardship program at a community hospital. Am. J. Health Syst. Pharm. 2014, 71, 943-949. [CrossRef]

78. Tamma, P.D.; Avdic, E.; Keenan, J.F.; Zhao, Y.; Anand, G.; Cooper, J.; Dezube, R.; Hsu, S.; Cosgrove, S.E. What is the more effective antibiotic stewardship intervention: Preprescription authorization or postprescription review with feedback? Clin. Infect. Dis. 2017, 64, 537-543.

79. Al-Hasan, M.N.; Eckel-Passow, J.E.; Baddour, L.M. Influence of referral bias on the clinical characteristics of patients with Gram-negative bloodstream Infection. Epidemiol. Infect. 2011, 139, 1750-1756. [CrossRef]

80. Antimicrobial Use and Resistance Module. 2019. Available online: https:/www.cdc.gov/nhsn/PDFs/ pscManual/11pscAURcurrent.pdf (accessed on 1 June 2019).

81. van Santen, K.L.; Edwards, J.R.; Webb, A.K.; Pollack, L.A.; O’Leary, E.; Neuhauser, M.M.; Srinivasan, A.; Pollock, D.A. The standardized antimicrobial administration ratio: A new metric for measuring and comparing antibiotic use. Clin. Infect. Dis. 2018, 67, 179-185. [CrossRef]

(C) 2019 by the authors. Licensee MDPI, Basel, Switzerland. This article is an open access article distributed under the terms and conditions of the Creative Commons Attribution (CC BY) license (http://creativecommons.org/licenses/by/4.0/). 